\title{
Tension pneumothorax on extracorporeal membrane oxygenation leading to significant pneumoperitoneum.
}

\author{
Hitoshi Hirose \\ Thomas Jefferson University \\ Nicholas C. Cavarocchi \\ Thomas Jefferson University \\ Kathleen Holoyda \\ Thomas Jefferson University
}

Follow this and additional works at: https://jdc.jefferson.edu/surgeryfp

Part of the Surgery Commons

\section{Let us know how access to this document benefits you}

\section{Recommended Citation}

Holoyda K, Cavarocchi NC, Hirose H. Tension pneumothorax on extracorporeal membrane oxygenation leading to significant pneumoperitoneum. Open Cardiovasc Thorac Surg 2012;5:31-34.

This Article is brought to you for free and open access by the Jefferson Digital Commons. The Jefferson Digital Commons is a service of Thomas Jefferson University's Center for Teaching and Learning (CTL). The Commons is a showcase for Jefferson books and journals, peer-reviewed scholarly publications, unique historical collections from the University archives, and teaching tools. The Jefferson Digital Commons allows researchers and interested readers anywhere in the world to learn about and keep up to date with Jefferson scholarship. This article has been accepted for inclusion in Department of Surgery Faculty Papers by an authorized administrator of the Jefferson Digital Commons. For more information, please contact: JeffersonDigitalCommons@jefferson.edu. 


\title{
Tension Pneumothorax on Extracorporeal Membrane Oxygenation Leading to Significant Pneumoperitoneum
}

\author{
Kathleen Holoyda, Nicholas C. Cavarocchi and Hitoshi Hirose \\ Department of Surgery, Thomas Jefferson University, Philadelphia, PA, USA
}

\begin{abstract}
Veno-venous and veno-arterial extracorporeal membrane oxygenation (ECMO) therapy is used to support the cardiac and pulmonary systems in the setting of acute failure. Maintaining adequate ECMO flow is crucial for the success of the therapy. Sudden decrease in venous return on ECMO has multiple etiologies, such as intravascular hypovolemia, malposition or kink of the venous cannula, suction occlusion of a cannula, and venous or arterial thrombi. Pathology within the chest, including pneumothorax, tension hemothorax and pericardial tamponade, may also decrease the ECMO flow because of compression of the cannula and decreased atrial volume. Air from a tension pneumothorax may be transmitted from the pleural space to the pericardial and contralateral pleural spaces, as well as the peritoneal cavity if significant pressure is applied to either side of the diaphragm, even without diaphragmatic disruption. The case presented here represents a unique presentation of sudden and sustained decrease of ECMO flow secondary to tension pneumothorax, as well as pneumoperitoneum, following a central venous catheter insertion.
\end{abstract}

Keywords: ECMO, hemodynamics, pneumoperitoneum, pneumothorax.

\section{INTRODUCTION}

Extracorporeal membrane oxygenator (ECMO) therapy is used as a temporary measure to support the cardiac and pulmonary systems in acute failure. Two different configurations of ECMO exist, including veno-arterial and veno-venous ECMO. Veno-arterial ECMO (VA-ECMO) can be used for both cardiac and respiratory support and involves draining deoxygenated blood from the venous system and returning oxygenated blood to the arterial system. VAECMO thus performs the oxygenation function of the lungs as well as the perfusion function of the heart. Veno-venous ECMO (VV-ECMO) is used in cases of respiratory failure, in which deoxygenated blood is drained from the venous system and oxygenated blood is returned to the venous system. VV-ECMO thus performs the oxygenating function of the lungs [1].

Flow of ECMO may decrease if the arterial or venous cannula is obstructed or compressed. Common causes of decreased ECMO flow include hypovolemia that responds to fluid challenge or malpositioning of a cannula resulting in obstructed flow. Compression can also be precipitated by a sudden change of intra-thoracic pressure. Tension pneumothorax may constrict the pericardium leading to decreased venous return and decrease of the ECMO flow, similar to tamponade physiology of tension pneumothorax on a functioning heart. Cardiac tamponade can decrease ECMO flow via a similar mechanism.

The increased intra-thoracic pressure from pneumothorax, especially tension pneumothorax, can spread across

*Address correspondence to this author at the Thomas Jefferson University, 1025 Walnut Street Room 605, Philadelphia, PA 19107, USA; Tel: 215955-5654; Fax: 215-955-6010; E-mail: Hitoshi.Hirose@jefferson.edu the mediastinum to the contralateral pleural space or through the diaphragm into the peritoneal space. Incomplete fusion of the pleura or congenital fenestrations creates a conduit for air between the pleural spaces without sternotomy or surgical intervention. In the setting of increased pleural cavity pressure, air can transfer into the peritoneum through diaphragmatic disruptions. Without a disruption in the diaphragm or trauma, spontaneous pneumoperitoneum, which can be managed conservatively, may also occur.

We report on our experience with a patient supported on VA-ECMO who developed an acute decrease of ECMO flow resulting in hypotension from a tension pneumothorax and pneumoperitoneum, following an attempted left internal jugular central venous catheter placement.

\section{CASE PRESENTATION}

A 56 year-old male with a history of non-ischemic dilated cardiomyopathy developed decompensated heart failure with episodes of sustained ventricular tachyarrhythmia complicated by acute renal failure. The patient was placed on VA-ECMO using the femoral vessels to bridge the patient either to a more permanent mechanical support device or to heart transplantation.

Initially, the patient maintained adequate ECMO flows of $6 \mathrm{~L} / \mathrm{min}$ and trans-esophageal echocardiogram confirmed correct positioning during placement. Between 01:00 and 03:00 on post-operative day 1, twelve hours post-operation, the ECMO flow decreased to $2.8-3.5 \mathrm{~L} / \mathrm{min}$. Volume in the form of $2.5 \mathrm{~L}$ of $5 \%$ albumin was given in $500 \mathrm{~mL}$ increments, resulting in a transient improvement of the ECMO flow. The ECMO venous cannula was manipulated to optimize return after the fluid challenge failed to increase flow. The ECMO flow stabilized to a rate of $4.0 \mathrm{~L} / \mathrm{min}$ until $04: 30$ on post-operative day 2 , when it again decreased 
to $2.5-3.0 \mathrm{~L} / \mathrm{min}$. The venous cannula was again manipulated at the bedside. The ECMO flow transiently improved to 3.0-3.3 L/min and the patient was brought to the cardiac catheterization laboratory at $06: 00$ for fluoroscopic positioning of the ECMO venous cannula. The cannula was found to be kinked and was successfully re-positioned under fluoroscopy. The patient suddenly became hemodynamically unstable in the cardiac catheterization laboratory while left internal jugular central venous access was attempted. Immediately after line placement, the ECMO flow decreased from $4.5 \mathrm{~L} / \mathrm{min}$ to $3.0 \mathrm{~L} / \mathrm{min}$ despite optimal placement of cannula; mean arterial pressure decreased from $80 \mathrm{~mm} \mathrm{Hg}$ to $60 \mathrm{~mm} \mathrm{Hg}$. An arterial blood gas was drawn at 09:15, revealing a metabolic acidosis with a $\mathrm{pH}$ of $7.16, \mathrm{PaCO} 2$ of $58 \mathrm{~mm} \mathrm{Hg}, \mathrm{PaO} 2$ of $375 \mathrm{~mm} \mathrm{Hg}$, bicarbonate level of 18 $\mathrm{mmol} / \mathrm{L}$, compared to a $\mathrm{pH}$ of $7.30, \mathrm{PaCO} 2$ of $41 \mathrm{~mm} \mathrm{Hg}$, $\mathrm{PaO} 2 \mathrm{~m} 426 \mathrm{~mm} \mathrm{Hg}$, bicarbonate level of $20 \mathrm{mmol} / \mathrm{L}$ drawn at 07:50. The drapes were removed and it was noted the patient's abdomen had become significantly distended.

At 11:30, lactate level increased to $6.9 \mathrm{mmol} / \mathrm{L}$ from $2.3 \mathrm{mmol} / \mathrm{L}$ at $01: 30$ on same day. Diminished breath sounds were noted bilaterally on physical examination. A chest radiograph was immediately obtained and revealed a large bilateral pneumothorax (Fig. 1). A left-sided chest tube was placed under the assumption that the right pneumothorax was related to the large left pneumothorax and that the right pneumothorax would resolve with the placement of a single, left-sided chest tube. After the placement of the chest tube, the ECMO flow improved from $3.0 \mathrm{~L} / \mathrm{min}$ to $4.7 \mathrm{~L} / \mathrm{min}$. The patient's abdomen was still distended at this time. Due to the metabolic acidosis and elevated lactate, there was a concern for abdominal pathology. The patient was sent to computed tomography (CT) scan at 19:07, which revealed a right tension pneumothorax with mediastinal shift (Fig. 2) and a large amount of pneumoperitoneum (Fig. 3). A right-sided chest tube was placed, which further increased the ECMO flow to $4.8 \mathrm{~L} / \mathrm{min}$. The patient underwent emergency bedside exploratory laparotomy at 22:00 on post-operative day 2 to rule out abdominal pathology due to his elevated lactate level, metabolic acidosis, and his physical examination. No intraperitoneal pathology was discovered.

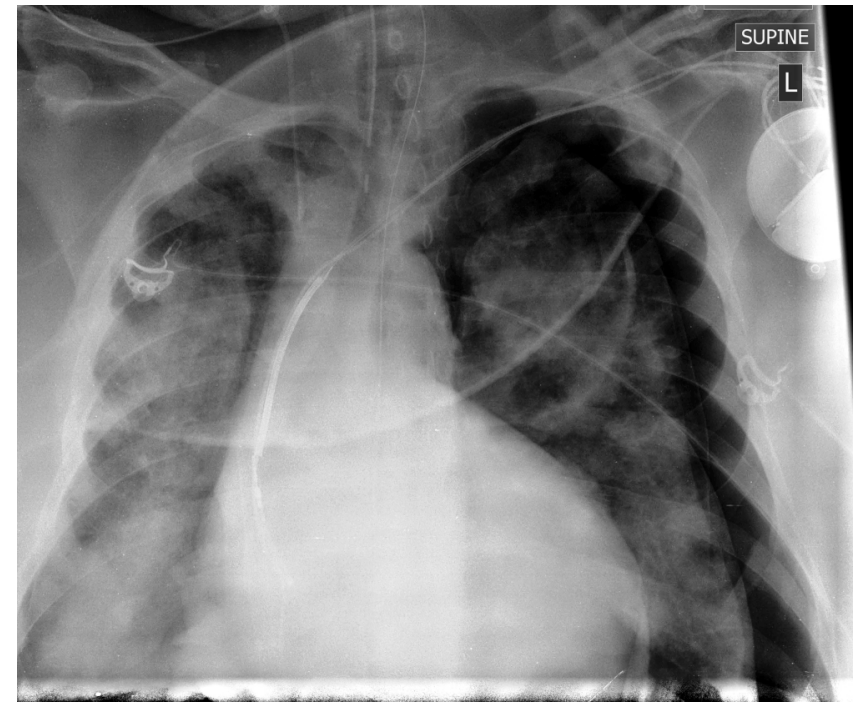

Fig. (1). Chest x-ray shows bilateral pneumothorax.

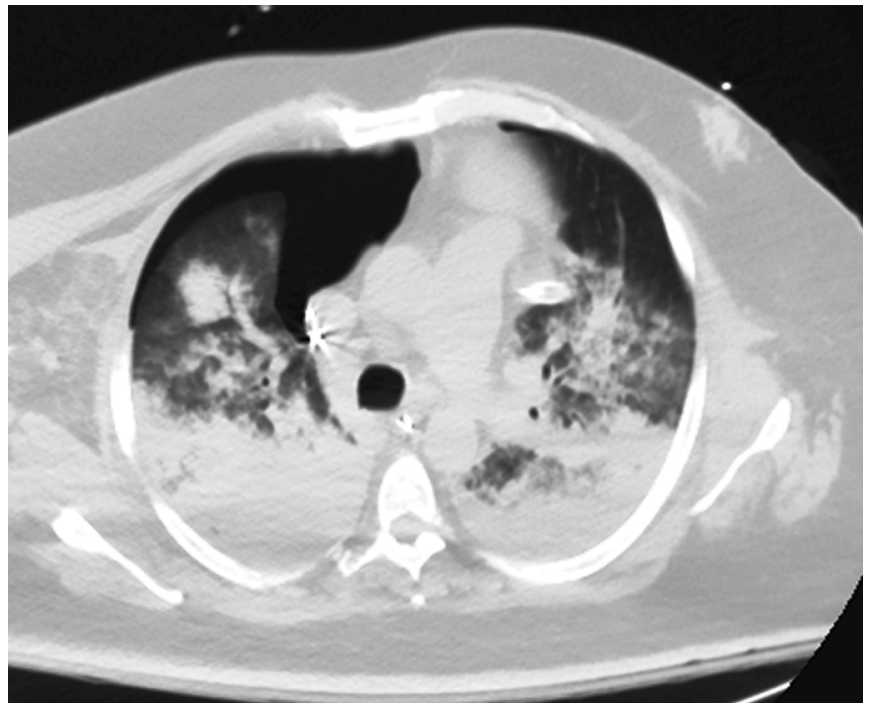

Fig. (2). Axial CT image of the chest shows tension right pneumothorax.

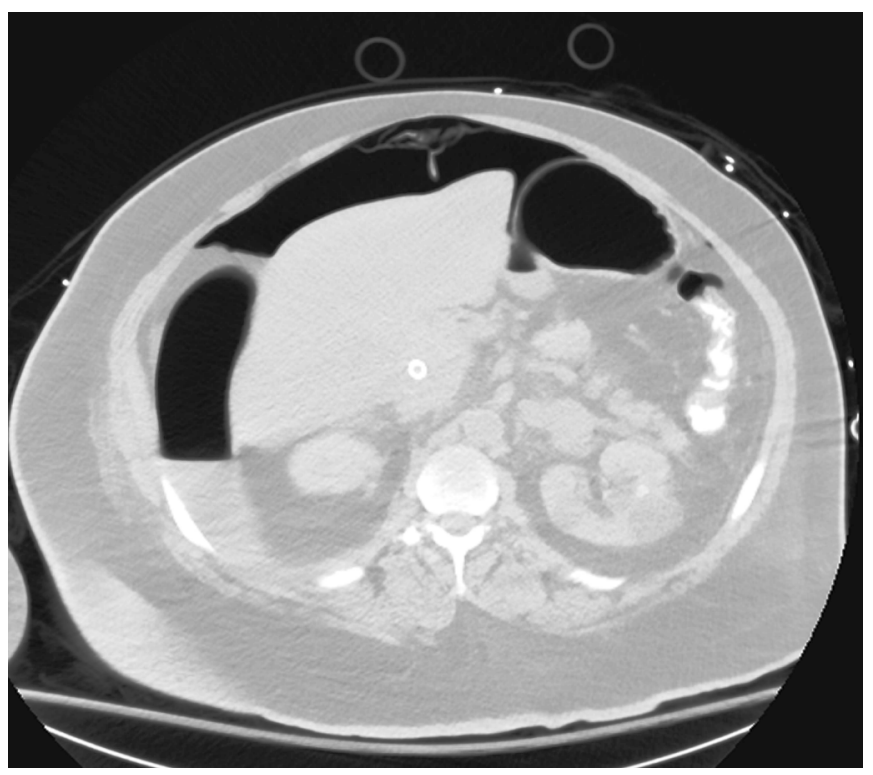

Fig. (3). Axial CT image of the abdomen shows significant pneumoperitoneum.

\section{DISCUSSION}

The case presented here reveals two important manifestations. First, a decrease in ECMO flow can be a sign of significant intra-thoracic pathology. Second, pneumoperitoneum may be the result of severe tension pneumothorax without an obvious defect in the diaphragm.

The maintenance of adequate ECMO flow is a frequent issue encountered during this therapy. Initial technical issues must be considered, including hypovolemia or malposition of the cannula causing an obstruction. These issues can be addressed with an initial fluid challenge. If no improvement in flow is noted after the administration of fluid, imaging and re-positioning of the cannulas is recommended [1]. When the ECMO flow initially dropped to $2 \mathrm{~L} / \mathrm{min}$, the patient was resuscitated with $2.5 \mathrm{~L}$ of $5 \%$ albumin. The flow did not return to the flow of $6 \mathrm{~L} / \mathrm{min}$ that had initially been maintained as expected, ruling out hypovolemia as a cause of 
the decreased ECMO flow. Two attempts were therefore made at the bedside to re-position the ECMO cannulas with transient improvement of flow, until the cannulas were repositioned under fluoroscopy in the cardiac catheterization laboratory. It is believed that the initial decrease in ECMO flow was secondary to the malposition of the venous cannula until the pneumothorax was created in the cardiac catheterization laboratory during attempted left internal jugular central venous access.

The decrease in ECMO flow secondary to significant intra-thoracic pathology including pneumothorax, hemothorax, and pericardial tamponade is well-described in neonatal ECMO patients [2]. However, it has not been clearly described in the adult ECMO population. The increased pressure from tension pneumothorax significantly increases the intra-thoracic pressure, which decreases venous return to the right atrium and the venous cannula, causing decreased ECMO flow. Decreased ECMO flow caused systemic hypotension and hypoperfusion, leading to metabolic acidosis. The mechanism is similar to that of tension pneumothorax in the setting of a normal heart, where increased intra-thoracic pressure places pressure on the pericardium and decreases venous return to the right atrium.

Pneumothorax spreading across the mediastinum is common in the setting of post-sternotomy and significant pulmonary disease [3]. However, it is also important to recognize that there can be a communication between the right and left pleural spaces without any previous intervention. This communication can represent incomplete fusion of the pleura or small congenital fenestrations [4]. In this case, we believed the bilateral pneumothoraces were a result of a single injury, as central venous catheter placement had been attempted multiple times only on the left side. Therefore a single chest tube was placed under the assumption that it would resolve both pneumothoraces. The patient's abdominal distension developed acutely and further imaging was obtained to evaluate for the resolution of the pneumothorax as well as to evaluate for abdominal pathology. The CT scan revealed significant pneumoperitoneum and the remaining right-sided thoracic pathology. The amount of air in the abdomen and sudden metabolic acidosis experienced in this case was significant enough to suspect visceral pathology, which prompted the surgeon to perform a bed-side exploratory laparotomy.

Few cases of pneumoperitoneum secondary to tension pneumothorax have been described, although numerous pneumothoraces secondary to pneumoperitoneum have been reported [5-8]. Spontaneous pneumoperitoneum secondary to blunt chest trauma has only been reported in severe blunt thoracic trauma in a patient without diaphragm injury [9]. Approximately $10 \%$ of pneumoperitoneum is attributed to "spontaneous pneumoperitoneum," or "free air not associated with a perforated viscera." [9] Spontaneous pneumoperitoneum is often managed conservatively, while pneumoperitoneum with perforated viscus necessitates emergent surgery $[10,11]$. The primary concern for this patient was the occurrence of perforated viscus secondary to visceral ischemia. The patient was also at increased risk for acute ischemic bowel secondary to embolism, as the ECMO oxygenator can be the source for thromboembolism. To differentiate spontaneous pneumoperiteonum and pneumoperitoneum secondary to perforated viscus, clinical correlation is required. However, in a patient on ECMO it is difficult to assess the clinical manifestations of intraabdominal pathology due to the frequent use of sedatives and paralytic agents, the persistent inflammatory state that is a direct result of ECMO, the metabolic acidosis related to the primary cause of the cardiopulmonary failure, and the difficult transport of the patient for appropriate imaging studies. As a result, based on the acute abdominal distention, imaging studies, increasing lactate level, and worsening metabolic acidosis of our patient, an unnecessary bed-side exploratory laparotomy was performed.

The above case presentation is unique for two reasons. The first feature recognizes decreased ECMO flow as an indication of intra-thoracic pathology in an adult patient. The second feature recognizes spontaneous pneumoperitoneum in the setting of intra-thoracic pathology without diaphragmatic disruption, which can be managed conservatively.

\section{ACKNOWLEDGEMENT}

Authors thank for Pawel Karbowski, MS and Joseph Miessaru, MS for data collection.

\section{CONFLICT OF INTEREST}

The authors confirm that this article content has no conflict of interest.

\section{REFERENCES}

[1] Marasco SF, Lukas G, McDonald M, McMillan J, Ihle B. Review of ECMO (Extra Corporeal Membrane Oxygenation) Support in Critically Ill Adult Patients. Heart Lung Circ 2008; 17s: S41-7.

[2] Zwischenberger JB, Cilley RE, Hirschl RB, Heiss KF, Conti VR, Bartlett RH. Life-threatening intrathoracic complications during treatment with extracorporeal membrane oxygenation. J Pediatr Surg 1988; 2: 599-604.

[3] Jensen NM, Balslev E, Mortensen DP. Bilateral pneumothorax following transthoracic fine needle aspiration biopsy. Eur J Respir Dis 1987; 71: 479-80.

[4] Gruden JF, Stern EJ. Bilateral pneumothorax after percutaneous transthoracic needle biopsy. Chest 1994; 105: 627-8.

[5] Akoglu H, Coban E, Guneysel O. Tension pneumoperitoneum complicated with tension pneumothorax in a patient with diaphragmatic eventration. BMJ Case Rep 2012; 2012. Pii: bcr0120125512. Available from: http://casereports.bmj.com/conten $\mathrm{t} / 2012$ /bcr.01.2012.5512.long

[6] Chan YC, Tsai YC, Fang SY. Subcutaneous emphysema, pneumothorax, pneumomediastinum, and pneumoperitoenum during colonoscopic balloon dilatation: a case report. Kaohsiung J Med Sci 2010; 26: 669-72.

[7] Kipple JC. Bilateral tension pneumothoraces and subcutaneous emphysema following colonoscopic polypectomy: a case report and discussion of anesthesia considerations. AANA J 2010; 78: 462-7.

[8] Menendez P, Padilla D, Villarejo P, Garcia A. Pneumoperitoneum, pneumoretroperitoneum, bilateral pneumothorax, pneumomediastinum and subcutaneous emphysema due to ERCP. Rev Gastroenterol Peru 2012; 32: 94-7.

[9] Urso G, Palladino E, Andriulo N, et al. Spontaneous pneumoperitoneum: a case secondary to thoracic trauma. Minerva Chir 2007; 62: 497-502. 
[10] Mezghebe HM, Leffall LD Jr, Siram SM, Syphax B. Asymptomatic pneumoperitoneum diagnostic and therapeutic dilemma. Am Surg 1994; 60: 691-4.
[11]

Williams NM, Watkin DF. Spontaneous pneumoperitoneum and other nonsurgical causes of intraperitoneal free gas. Postgrad Med J 1997; 73: 531-7.

(C) Holoyda et al.; Licensee Bentham Open.

This is an open access article licensed under the terms of the Creative Commons Attribution Non-Commercial License (http://creativecommons.org/licenses/by$\mathrm{nc} / 3.0 /$ ) which permits unrestricted, non-commercial use, distribution and reproduction in any medium, provided the work is properly cited. 